\title{
PENGARUH OTAGO EXERCISE PROGRAMME TERHADAP RENTANG GERAK SENDI PADA LANJUT USIA
}

\author{
Erna Ariyanti Kurnianingsih \\ Kementerian Kesehatan Politeknik Kesehatan Surakarta Jurusan Okupasi Terapi
}

\begin{abstract}
Otago Exercise Programme-Range of Motion - Elderly. Subject's characteristic of this study are elderly with a different style of dressing and they prefer barefoot when doing exercises. Otago Exercise Programme (OEP) is one of exercise type to reduce fall risk in elderly. OEP was an important exercise to prevent fall risk. This programme have been delivered in west country and it had improved the elder people's balance skill. The aim of this study is to analyse the effect of OEP to range of motion of the elderly. This is a quasi-experimental research with a nonrandomized control group pretest posttest design. The subjects of this study are 24 elderly of treated group and 24 elderly of control group. Subject's inclusion criteria are: healthy female elderly of local government social institution care for the elderly in Sleman Yogyakarta with the age of 60-75 years old. The subject's range of motion of knee flexion, plantar flexion and dorsi flexion of the ankle range of motion were measured by goniometer. Subject on treated group are given Otago Exercise Programme 3 times a week, 30 minutes each session for 8 weeks. Both subject were being measured their Range of Motion before and after research. Independent t-test was used to compared the result. There is no differences between ankle dorsi and plantar flexion range of motion before and after research on both treated or control group $(p<0,05)$. OEP doesn't have impact on range of motion of the elderly.
\end{abstract}

Keywords: Otago Exercise Programme-Range of Motion- Elderly

Abstrak: Otago Exercise Programme-Rentang Gerak Sendi- Lansia. Karakteristik sampel penelitian ini adalah lansia yang lebih senang tidak beralaskaki saat melakukan olahraga. Otago exercise programme (OEP) merupakan salah satu latihan untuk mengurangi resiko jatuh pada lansia. Program ini sudah dilakukan di Negara-negara barat dan dapat meningkatkan keterampilan keseimbangan bagi lansia. Penelitian ini bertujuan untuk menganalisa efek OEP terhadap rentang gerak sendi lansia. Penelitian ini menggunakan metode quasi experimental nonrandomized control group pretest posttest design. Sampel penelitian ini terdiri dari 24 lansia pada kelompok perlakuan dan 24 lansia kelompok control. Kriteria inklusinya adalah lansia wanita yang sehat yang tinggal di Panti Wreda milik pemerintah daerah diSleman Yogyakarta dengan usia antara 60-75 tahun. Rentang gerak sendi akan diukur dengan goniometer. Kelompok perlakuan diberikan latihan OEP tiga kali seminggu dengan durasi 30 menit per sesi selama 8 minggu. Sampel pada kedua kelompok tersebut akan diukur RGSnya sebelum maupun sesudah perlakuan. Rerata RGS sampel akan dianalissi dengan independent ttest. Tidak ada perbedaan rentang gerak sendi dorsifleksi dan plantarfleksi pergelangan kaki baik sebelum maupun setelah perlakuan pada kelompok perlakuan dan kelompok 
control $(p<0,05)$. Tidak ada pengaruh Otago exercise programe terhadap rentang gerak sendi lansia

Keyword: Otago Exercise Programme-Rentang Gerak Sendi- Lansia

\section{PENDAHULUAN}

Proses degenerasi merupakan proses fisiologis yang terjadi pada lansia. Seiring pertambahan usia lansia, maka risiko jatuh juga meningkat. Sebagai upaya pencegahan jatuh diperlukan latihan yang mampu mengurangi risiko jatuh, salah satu latihan tersebut adalah Otago Exercise Programme (OEP).Penelitian dengan OEP sudah pernah dilakukan di luar negeri tetapi karakteristik subjek penelitian tersebut sangat berbeda dengan subjek pada penelitian ini.Subjek pada penelitian ini adalah lansia yang mempunyai perbedaan budaya dalam berpakaian dan tidak menggunakan alas kaki saat latihan.

Tahun 2020 diperkirakan jumlah lansia akan meningkat menjadi 28.8 juta jiwa atau 11,34 \% dari total jumlah penduduk(Kemenkes RI, 2012). Menurut data statistik Daerah Istimewa Yogyakarta tahun 2011 terdapat lansia sejumlah 29,724 jiwa. Tahun 2012 jumlah lansia di Yogyakarta menjadi 44,425 jiwa atau 9,7 $\%$ dari total jumlah penduduk(Badan Pusat Statistik, 2012). Insiden jatuh pada populasi lansia adalah 28-35 \% pada lansia berumur lebih dari 65 tahun, dan $32-42 \%$ pada lansia yang berumur lebih dari 75 tahun. Lansia yang mempunyai riwayat jatuh berisiko lebih besar mengalami jatuh kembali dan sekitar $30 \%$ dari kasus jatuh menyebabkan terjadinya injuri yang memerlukan perhatian medis dan $10 \%$ kasus jatuh menyebabkan terjadinya patah tulang (Kuptniratsaikul et $a l, 2011)$. Menurut hasil penelitian Tuti (2012) di Panti Sosial Tresna Wredha
(PSTW) Abiyoso Pakem Yogyakarta, proporsi jatuh lansia di PSTW tersebut adalah 52,2\%. Oleh karena itu diperlukan upaya pencegahan kejadian jatuh dengan memperbaiki

\section{The Otago Exercise Programme} (OEP) adalah sebuah latihan yang didesain bagi lansia untuk mencegah risiko jatuh, yang dilakukan dengan penguatan otot dan latihan keseimbangan (Taylor \& Stretton, 2004). Karakteristik lansia di Indonesia sangat berbeda dengan lansia di luar negeri, lansia di Indonesia lebih senang tidak beralaskaki saat berolah raga sangat berbeda dengan lansia di luar negeri yang terbiasa bersepatu saat latihan atau berolah raga. Tingginya risiko jatuh pada lansia dan karakteristik yang sangat berbeda inilah yang membuat penulis tertarik untuk meneliti apakah OEP dapat memberikan manfaat yang sama pada lansia di Indonesia.

Manusia sebagai makhluk bipedal yang mudah jatuh, dan tingginya kejadian jatuh pada lansia di Indonesia inilah yang mendasari pentingnya upaya pencegahan jatuh dengan perbaikan keseimbangan lansia yang salah faktornya adalah rentang gerak sendi. Berdasarkan latar belakang penelitian ini dapat dirumuskan masalah penelitian ini sebagai berikut: apakah Otago Exercise Programme dapat meningkatkan rentang gerak sendi lansia. Penelitian ini diharapkan dapat memberikan manfaat untuk: 1). Lansia di Indonesia: menganalisis pengaruh Otago Exercise Programme terhadap rentang gerak sendi sebagai salah satu factor yang mempengaruhi keseimbangan pada lansia 
untuk mengurangi risiko jatuh; 2). Manfaat praktis penelitian ini adalah OEP dapat diterapkan pada lansia di Indonesia untuk pencegahan risiko jatuh; 3). Manfaat teoritis untuk keilmuan : penelitian ini diharapkan dapat memberikan manfaat untuk pengembangan ilmu yang berkaitan dengan muskuloskeletal dan lansia.Tujuan penelitian ini adalah menganalisis pengaruh $O E P$ terhadap rentang gerak sendi pada lansia.

\section{METODE PENELITIAN}

Jenis penelitian ini adalah penelitian quasi eksperimental dengan rancangan nonrandomized control group pretest posttest design. Penelitian dilakukan dengan memberikan perlakuan pada sekelompok subjek berupa latihan Otago Exercise Programme, yang dibandingkan dengan kelompok kontrol yang tidak mendapatkan perlakuan.

Variabel bebas pada penelitian ini adalah OEP, variabel terikat berupa rentang gerak sendi. Populasi penelitian ini adalah lansia di Panti Sosial Tresna Werdha (PSTW) Unit Abiyoso Pakem Sleman Yogyakarta yang berjumlah 126 orang.Teknik pengambilan subjek penelitian dengan constitutive sampling dengan kriteria inklusi lansia sehat klinis berusia 60 tahun sampai 75 tahun. Alat penelitian yang digunakan dalam penelitian ini adalah goniometer, sandbag $1 \mathrm{~kg}$, meja , kursi.

Setelah dilakukan pretest, subjek pada kelompok perlakuan diberikan latihan Otago Exercise Programme (OEP) sebanyak 3 kali seminggu dengan durasi 30 menit per sesi selama 8 minggu. Pada minggu ke sembilan dilakukan post test dengan instrumen yang sama seperti pretest baik pada subjek kelompok perlakuan maupun kelompok kontrol.Analisis data dilakukan dengan uji normalitas data dengan uji Shapirowilk.Hasil uji normalitas data pada kedua kelompok normal sehingga dilakukan uji komparatif untuk dua sampel tidak berpasangan dengan independent t-test dengan kemaknaan $\mathrm{p}<0,05$.

\section{HASIL PENELITIAN}

\section{Tabel 1}

\section{Karakteristik Subjek Penelitian}

Kelompok Perlakuan dan Kontrol Pada Awal Penelitian

\begin{tabular}{|c|c|c|c|c|c|}
\hline \multirow[t]{2}{*}{ Variabel } & \multicolumn{2}{|c|}{$\begin{array}{l}\text { Kelompok } \\
\text { perlakuan }\end{array}$} & \multicolumn{2}{|c|}{$\begin{array}{l}\text { Kelompok } \\
\text { kontrol }\end{array}$} & \multirow[t]{2}{*}{$p$} \\
\hline & $x+s d$ & & $x+s d$ & & \\
\hline Usia (th) & $\begin{array}{c}69,79 \pm \\
4,908\end{array}$ & & $\begin{array}{c}70,50 \pm \\
3,707\end{array}$ & & 0,575 \\
\hline $\begin{array}{l}\text { Tinggi } \\
\text { badan } \\
(\mathrm{cm})\end{array}$ & $\begin{array}{l}149,92 \\
6,426\end{array}$ & \pm & $\begin{array}{l}153,08 \\
4,708\end{array}$ & \pm & 0,058 \\
\hline $\begin{array}{l}\text { Berat } \\
\text { badan } \\
(\mathrm{kg})\end{array}$ & $\begin{array}{l}49,00 \\
3,923\end{array}$ & \pm & $\begin{array}{l}50,29 \\
3,00\end{array}$ & \pm & 0,207 \\
\hline $\begin{array}{l}\text { Indek } \\
\text { masa } \\
\text { tubuh } \\
\left(\mathrm{kg} / \mathrm{m}^{2}\right)\end{array}$ & $\begin{array}{l}21,8283 \\
1,62198\end{array}$ & \pm & $\begin{array}{l}21,59 \\
1,27587\end{array}$ & \pm & 0,584 \\
\hline
\end{tabular}

Tabel 1 menunjukkan karakteristik subjek penelitian pada kelompok perlakuan dan kelompok kontrol di awal penelitian. Secara statistik, usia, tinggi badan, berat badan, indek massa tubuh, kelompok perlakuan dan kontrol tidak mempunyai perbedaan yang bermakna $(p>0,05)$. Sehingga dapat disimpulkan bahwa kemampuan awal subjek pada kedua kelompok sama. 
Tabel 2

Hasil Uji Paired T-Test Rentang Gerak Sendi Fleksi Lutut, Plantar Fleksi dan Dorsi Fleksi Pergelangan Kaki Subjek Kelompok Perlakuan dan Kelompok Kontrol pada Awal dan Akhir Penelitian

\begin{tabular}{|c|c|c|}
\hline Variabel & $\begin{array}{lr}\text { Kelompok } & \text { Perlaku } \\
x \pm s d & x \pm s d \\
\text { awal } & \end{array}$ & $\begin{array}{l}\text { an } \\
\text { akhir }\end{array}$ \\
\hline $\begin{array}{l}\text { RGS Fleksi } \\
\text { RGS } \\
\text { Plantar } \\
\text { Fleksi } \\
\text { Pergelang } \\
\text { an } \\
\text { Kaki }\left(^{0}\right) \\
\end{array}$ & $\begin{array}{l}\text { ILufų } 1^{0} \pm 4,032 * * \\
32,92 \pm 2,518\end{array}$ & $\begin{array}{l}120,21 \pm 5,801 * * \\
33,54 \pm 2,750\end{array}$ \\
\hline $\begin{array}{l}\text { RGS Dorsi } \\
\left({ }^{0}\right)\end{array}$ & Fłe,ks & $\begin{array}{l}\text { Kaki } \\
16,33 \pm 3,329 *\end{array}$ \\
\hline Variabel & $\begin{array}{l}\text { Kelompok Kontrol } \\
x \pm s d \quad x \pm s d \\
\text { awal }\end{array}$ & akhir \\
\hline
\end{tabular}

RGS Fleksi LuBu1 3표 $3,234 *$

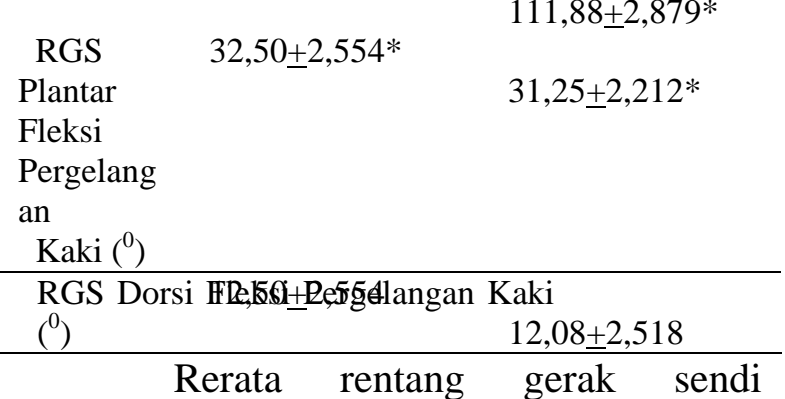

maksimal plantar fleksi pergelangan kaki subjek kelompok perlakuan antara awal dan akhir perlakuan meningkat, dengan nilai $p>0,05$, artinya tidak terdapat perbedaan yang bermakna rentang gerak sendi maksimal plantar fleksi pergelangan kaki subjek kelompok perlakuan antara awal dan akhir penelitian. Sedangkan rerata rentang gerak sendi maksimal plantar fleksi pergelangan kaki subjek kelompok kontrol antara awal dan akhir penelitian turun, dengan nilai $\mathrm{p}<0,05$. Hal ini berarti terdapat perbedaan yang bermakna rentang gerak sendi maksimal plantar fleksi pergelangan kaki subjek kelompok kontrol antara awal dan akhir penelitian.

Tabel 2 juga menunjukkan rerata rentang gerak sendi maksimal dorsi fleksi pergelangan kaki subjek kelompok perlakuan antara awal dan akhir penelitian meningkat, dengan nilai $\mathrm{p}<0,05$. Hal ini berarti terdapat perbedaan yang bermakna rentang gerak sendi maksimal dorsi fleksi pergelangan kaki subjek kelompok perlakuan antara awal dan akhir penelitian. Sedangkan rerata rentang gerak sendi maksimal dorsi fleksi pergelangan kaki subjek kelompok kontrol menurun, dengan nilai $p>0,05$. Hal ini berarti tidak terdapat perbedaan yang bermakna rentang gerak sendi maksimal dorsi fleksi pergelangan kaki subjek kelompok kontrol antara awal dan akhir penelitian.

\section{Tabel 3}

Hasil Uji Independent T-test Selisih

Rentang Gerak Sendi antara Subjek Kelompok Perlakuan dengan Kelompok Kontrol di Awal dan Akhir Penelitian.

$\begin{array}{lll}\text { Variabel } & \begin{array}{l}\text { Kelom } \\ \text { pok } \\ \text { Perlaku } \\ \text { an } \\ x \pm S D\end{array} & \begin{array}{l}\text { Kelom } \\ \text { Kok } \\ x \pm S D\end{array} \\ & 5.00 \pm & -1,25 \pm \\ & & 2,658 \\ \text { RGS Fleksi Lutut }\left(^{0}\right) & & \\ \text { RGS Plantar Fleksi Pergelangan Kaki }\left(^{0}\right) & 3,612 & \\ \text { RGS Dorsi Fleksi Pergelangan Kaki }\left(^{0}\right) & 0,63 \pm & 1,25 \pm \\ & 1,689 & 2,212 \\ & 0,21 \pm & 0,21 \pm \\ & 1,021 & 1,021\end{array}$

Tabel 3 di atas menunjukkan bahwa tidak terdapat perbedaan yang bermakna rentang gerak sendi plantar dan dorsi fleksi pergelangan kaki antara subjek di awal dan akhir penelitian antara 
kelompok perlakuan dengan subjek kelompok control $(p<0,05)$. Dengan demikian dapat disimpulkan bahwa latihan OEP tidak berpengaruh terhadap rentang gerak sendi lansia.Walaupun begitu pada penelitian ini rentang gerak sendi fleksi subjek kelompok perlakuan meningkat. Peningkatan rentang gerak sendi tersebut karena dalam OEP terdapat gerakan berikut ini: gerakan menekuk lutut dengan atau tanpa berpegangan, gerakan penguatan lutut bagian belakang, berjalan mundur dengan atau tanpa berpegangan, berjalan dan berputar, berdiri dengan satu kaki dengan atau tanpa berpegangan, berjalan mundur dengan tumit kaki depan menempel pada jari-jari kaki yang di belakang, berdiri dari posisi duduk dengan bantuan kedua tangan atau satu tangan, berdiri dengan satu kaki dengan atau tanpa berpegangan, naik tangga. Fleksibilitas sendi lutut kiri pada lansia meningkat setelah melakukan latihan rentang gerak sendi (Ulliya, Soempeno, \& Kushartanti, 2007) dan rentang gerak sendi aktif fleksi lutut pada individu yang berusia 60-74 tahun mempunyai rerata $131^{0}$ (Roach Miles, 1991).

\section{PEMBAHASAN}

Rentang gerak sendi plantar fleksi pergelangan kaki subjek kelompok perlakuan pada penelitian ini meningkat karena dalam OEP terdapat gerakan yang mampu meningkatkan rentang gerak sendi tersebut. Adapun gerakan tersebut adalah gerakan plantar fleksi pergelangan kaki, berdiri pada tumit dengan atau tanpa berpegangan, berjalan mundur dengan tumit kaki depan menempel jari-jari kaki belakang, berjalan dan berputar, berjalan naik tangga.
Sedangkan rentang gerak sendi maksimal dorsi fleksi subjek kelompok perlakuan meningkat.Hal itu terjadi karena dalam OEP terdapat gerakan dorsi fleksi pergelangan kaki, gerakan dorsi fleksi pergelangan kaki saat penguatan lutut, menekuk lutut dengan atau tanpa berpegangan, berjalan mundur dengan atau tanpa berpegangan, berdiri pada tumit, berjalan naik tangga. Imobilitas menyebabkan menurunnya massa dan kekuatan otot serta fleksibitas sekitar sendi (Jenkins,2005), dan sudut rentang gerak sendi maksimal pasif pada gerakan dorsi fleksi pergelangan kaki lansia adalah $10,3^{0}$ (Gajdosik et al., 2004).

Penurunan kekuatan otot mempengaruhi kemampuan individu mencapai rentang gerak sendi maksimal, tetapi pernyataan ini bertolak belakang dengan pendapat yang menyatakan bahwa penguluran statik yang dilakukan sebelum latihan tidak mempengaruhi kekuatan otot yang dicapai selama 10 minggu program latihan penguatan otot (Lustosaet al., 2010).Durasi penguluran mempengaruhi perubahan rentang gerak sendi (Feland et al., 2001) dan penguluran pada otot hamstrings selama 60 detik menghasilkan rentang gerak sendi yang lebih besar dan lebih bertahan lama (Ullya et al, 2007; Feland et al., 2001) . Persentase perubahan kelenturan badan dengan latihan 3 kali seminggu lebih besar daripada 2 kali seminggu(Budiharjo, Romi, \& Prakosa, 2005),

Gerakan persendian menyebabkan peningkatan aliran darah ke dalam kapsula sendi, latihan menyebabkan terjadinya gerakan sendi. Saat sendi digerakkan permukaan kartilago antara kedua tulang akan saling bergesekan. Penekanan pada kartilago mendesak air keluar dari matrik kartilago menuju cairan sinovia, bila 
tekanan berhenti maka air yang keluar dari matrik kartilago menuju cairan sinovia ditarik kembali dengan membawa nutrisi dari cairan synovia (Ullya et al. 2007). Rentang gerak sendi juga dipengaruhi oleh jenis kelamin dan usia, RGS lansia wanita lebih baik daripada lansia laki-laki, dan RGS usia tua pada umumnya lebih rendah daripada RGS usia muda (Ullya et $a l .$, 2007; Jenkins,2005).

\section{KESIMPULAN DAN SARAN}

Otago Exercise Programme terbukti tidak berpengaruh terhadap rentang gerak sendi fleksi lutut, dan keseimbangan. Disarankan untuk dilakukan penelitian lebih lanjut mengenai pengaruh latihan sensorik terhadap keseimbangan pada lansia.

\section{DAFTAR RUJUKAN}

Budiharjo, S., Romi, M.M., \& Prakosa, D. Pengaruh senam aerobik low impact intensitas sedang

terhadap kelenturan badan pada wanita lanjut usia tidak terlatih. Berkala Ilmu Kedokteran. 2005; 37(4):177182.

Feland, J. B., Myrer, J.W., Schulthies, S.S., Fellingham, G.W., Measom, G.W. The effect of

duration of the hamstring muscle group for increasing range of motion in people aged 65 year or older. Phys Ther. 2001;81: 1110-1117.

Gajdosik, R.L., Vander Linden, D.W., Mcnair, P.J., Riggin, T.J., Albertson, J.S., Mattick, D.J.,

Wegley, J.C. Slow passive stretch and release characteristics of the calf muscles of older women with limited dorsiflexion range of motion. J Clin Biomech.2004;19: 398-406.
Jenkins, L. Maximizing range of motion in older adults.J. Active Aging. 2005. Jan- Feb : 50-55.

Kementerian Kesehatan Republik Indonesia.Menuju tua, sehat, mandiri, dan produktif." Kesehatan yang baik memperpanjang usia dan kehidupan, Jakarta. 2012.

Kuptniratsaikul, V., Praditsuwan, R., Assantachai, P., Ploypetch, T., Udompunturak, S., Pooliam,

J. Effectiveness of simple balancing training program in elderly patient with history of frequents falls. Dove Press Journal : Clinical Interventions in Aging, 2011; 6:111-117.

Lustosa, L.P., Pacheco, M.G.M., Liu, A.L., Goncalves, W.S., Silva, J.P., Pereira, L.S.M. Impact

of static stretching on the gain in kneeextensor strength of communitydwelling older women after a training programme. Rev bras Fisoles. 2010;14(6): 497-502.

Roach, K. E., Miles, I. P. Normal hip and knee AROM the relation to age. Phys Ther, 1991;71:656-665.

Tuti, T.M.R. Proporsi dan faktor resiko kejadian 'jatuh' pada lansia di Panti Sosial Tresna Wredha (Skripsi). Fakultas Kedokteran Universitas Islam Indonesia, Yogyakarta.2012.

Ulliya, S., Soempeno, B., Kushartanti, B.M.W. Pengaruh latihan ROM terhadap fleksibilitas sendi lutut pada lansia di PW Wening Wardoyo Ungaran. Media Ners, 2007;1(2):72-77. 